\title{
Report on the Music Collection Assessment Summit
}

\section{April 21-23, 2021, University of Toronto (online) \\ Report by Janneka Guise, Director, University of Toronto Music Library}

The University of Toronto Music Library has undertaken a large-scale assessment of the music score collection. The team responsible for the assessment work consists of all the music librarians plus the music archivist:

- Trevor Deck, Collections Management Librarian, Music and Film

- James Mason, Digital Initiatives and Metadata Librarian

- Tim Neufeldt, Instruction Librarian and Circulation Supervisor

- Rebecca Shaw, Music Archivist

Apart from the fact that regular collection assessment is a best practice for libraries, we face specific, critical challenges that necessitate this work:

- We are out of shelf space in the Library, despite $30 \%$ of our collection having been moved to Downsview, the $U$ of $T$ Libraries' off-site shelving facility. We currently have a reactive approach whereby we weed one item for Downsview for every new acquisition we shelve. We want to be proactive: develop criteria for what stays in-house and what moves to Downsview; move a large number of materials to Downsview at once; use the criteria to direct new acquisitions to Downsview or to the Music Library as appropriate.

- The Faculty of Music began a space audit in 2019 in order to make a case to the Provost for a new building/renovation. The Music Library is located in the Faculty and is part of the space audit. We need to answer questions such as: How much space do we need, ideally? How much of the collection can move to Downsview? Which materials should remain onsite and why?

- We want to investigate the diversity in our collection: what percentage of compositions are written by women, by Black or Indigenous people, or people of colour? What countries of origin are represented in our collection? We hope to uncover and celebrate this diversity, understand the uniqueness and specialties of our collection, teach users how to search for these materials, and fill gaps in important areas.

The collection assessment work began with a literature review which taught us that although there are many approaches to weeding book and journal collections, there have been few published studies on how to weed music score collections. We expect to publish our literature review at a later date.

We decided to reach out to peer institutions to share ideas on music score collection assessment. We chose five peers based on similarity of music programming, size of enrollment, and size of music 
library collection: Harvard University, Yale University, Eastman School of Music, Indiana University Bloomington, and University of California at Los Angeles (UCLA). Librarians at all five institutions had taken a variety of approaches to music score collection assessment. We decided to hold a Summit: each institution would prepare a presentation and we would invite library workers, music and iSchool students and faculty to attend.

Planning began in the Fall of 2019. The peer group met in-person for an initial conversation at the Music Library Association conference in Norfolk, VA in February 2020. Once the pandemic hit and travel was restricted, it became clear that we would need to host the Summit virtually. In order to make the virtual event as engaging as possible, we asked the participating librarians to prepare prerecorded presentations as well as a virtual tour of their libraries. We posted the presentations and tours on the Summit website a week before the Summit began. Then we devoted the live Summit sessions to Question/Answer periods with each presenter.

We used our institutional Zoom account for the live sessions. Here is a list of speakers, institutions, and abstracts:

\section{Managing user expectations with an abundance of space}

Jim Farrington, University of Rochester, Eastman School of Music

The Sibley Music Library is the largest academic music library in North America. What started out in 1904 as a public music library in Rochester, Sibley merged its 9000 books and scores with the nascent Eastman School of Music in 1921. The following hundred years saw an explosion of acquisitions during which the library outgrew three physical spaces, opening the doors of its latest home in January 1989 . The current building has 45,000 square feet of space housing some 650,000 physical items. A survey done in 2000 reported that we had only used about $1 / 3$ of the available shelf space for the circulating collections (a statistic almost unimaginable in most libraries today). The long-standing support of the library from our administration combined with this abundance of shelf space for so much of the collection has led to interesting collection development decisions with implications for user services.

\section{What stays and what goes? Music Score Collection Assessment at the University of Toronto}

Trevor Deck, Jan Guise, James Mason, Tim Neufeldt and Rebecca Shaw, University of Toronto

The Music Library at the University of Toronto is out of space. Shelves are crowded, aisles are too narrow to navigate.We make use of the UTL @ Downsview off-site storage facility, where 
approximately one-third of our music score collection is located. The criteria and policies we use to determine what stays on-site and what goes to Downsview is outdated and not well communicated. With a capital project renovation on the horizon, we need a clear understanding of what our collection looks like now, and what we want it to look like in a future space. The University of Toronto Libraries are having important conversations about anti-racism and de-colonization in our spaces and collections, and we want to ensure our music score collection reflects the curricula and diverse programming of the Faculty of Music. Normal weeding criteria such as publication date and circulation count are not appropriate for music scores, and there is little music-specific direction to be gleaned from the library literature. Our team will share our process to date which includes data analysis and preparation for user surveys and focus groups.

\section{Acquiring Multiple Copies and Editions of Music Scores}

Keith Cochran, Indiana University, Bloomington

I frequently make decisions about the quantity and types of editions that we need for scores in our collection. Because we serve an unusually large and diverse community, I often acquire multiple copies and multiple editions of the same work in order to meet the demands of users. In my talk, I will focus on several different works that can serve as case studies that illustrate the kinds of questions that I must answer on a regular basis about collection development and management. It is my hope that these case studies will be helpful to other librarians who regularly confront similar situations.

\section{Collaborative Music Collections with Borrow Direct}

Sandi-Jo Malmon, Harvard University, Eda Kuhn Loeb Music Library and Ruthann Boles McTyre, Yale University, Gilmore Music Library

The collaborative collection development plan that began in 2009 with music librarians from the 7 academic libraries of the Borrow Direct partnership has expanded over the past 10 years to include a total of 13 participating music libraries including those from the Ivy League and from MIT, Johns Hopkins, Duke, the University of Chicago and Stanford. The cooperative collection development plan for purchasing scores of contemporary composers has remained robust and truly collaborative as it has been updated to represent more broadly diverse collecting practices shared across institutions. Malmon and McTyre will discuss the history of this partnership as well as ongoing work to keep the collaboration and the collections fresh and relevant. 


\section{Maximizing Limited Space for Music Scores}

Callie Holmes and Matthew Vest, University of California, Los Angeles, Herb Alpert School of Music

The UCLA Music Library's physical collections have grown over 56 years from 36,000 to over 400,000 items while remaining in the same location. Strategies for housing the collection in limited space have evolved over time, including adding shelves, maximizing collections spaces, and moving items to a remote storage facility. Currently, each year we deaccession or move to storage approximately the same number of items that we acquire. Our process involves using circulation statistics to identify candidates for removal followed by collaborative item-by-item consideration, factoring in characteristics that cannot be determined via statistics, such as condition, current faculty and student research interest, and equity, diversity, and inclusion.

We designed the program to take place over three days, from 2-5pm Eastern Time (Toronto time) in order to accommodate colleagues on the West Coast who wanted to attend. If we had held the Summit in person, we would have organized a tour of the Toronto Reference Library (a main branch of Toronto Public Library, or TPL) which holds the largest music score collection of any Canadian public library. It is within easy walking distance of the Faculty of Music. For the virtual Summit, we invited TPL to create a virtual tour, and they also had a spot on the program for a live Question/Answer period.

On the last day of the Summit we organized an open panel discussion with the six peer participants, followed by two hours of small group discussions using Zoom's breakout room feature. We crowdsourced the small group discussion topics during the first two days of the Summit, by posting a link to a shared document where attendees could type discussion themes as they thought of them. Eight topics were suggested, so we created four breakout rooms in the first hour, and the other four in the second hour. Attendees could move themselves between breakout rooms depending on what they wanted to discuss:

1. Small music collections: Score selection/weeding processes for smaller institutions with fewer than 100 music majors, limited budgets, and no off-site storage.

2. PDF Scores: How to implement a program for making PDF scores from composers available for download. Trevor and Houman discussed a project they started at $\mathrm{U}$ of $\mathrm{T}$, and I would love to hear more about it.

3. Climate change: mindfulness in our collection development and management practice. What do people do (or what can we dream up on the spot) to minimize carbon emissions (shipping \& digital data/materials storage), deforestation and chemical waste (paper making, printing, and binding), landfill waste management (weeded materials have to go somewhere) etc.

4. Collaborative collecting: Resource sharing / consortial buying 
5. Addressing anti-racism: Specifically: assessing/filling collection gaps on compositions by BIPOC composers and choices around identifying and weeding materials that include racist/outdated narratives.

6. Shelving and values: "What do we want people to see when they walk in?" Discuss the optics/balance of composer diversity on the shelves, and what our shelves say about our values.

7. Off-site retrievals: Communications and expectation management (internal and external audiences) when implementing a requesting program to accommodate collections separated from their circulation point.

8. Open Access Scores: How about open access publishing? UCLA mentioned open access scores.

The University of Toronto team took turns moderating the live Question/Answer sessions and the breakout room discussions.

We were delighted by the response to the Summit: over 200 people registered, from at least 10 countries. Approximately 80 people joined the live sessions on each of the three days of the Summit; some registrants were in time zones unconducive to joining live. We recorded the live sessions and saved the accompanying chat transcripts so we could mine them for themes and relevant resource links that may help us with future directions for our work. Following the Summit we sent a link to the recordings to all registrants along with a link to a post-Summit survey. 